\title{
Responses of the Human Brain to Mild Dehydration and Rehydration Explored In Vivo by 'H-MR Imaging and Spectroscopy
}

\author{
A. Biller, M. Reuter, B. Patenaude, G.A. Homola, F. Breuer, (DM. Bendszus, and A.J. Bartsch
}

\begin{abstract}
BACKGROUND AND PURPOSE: As yet, there are no in vivo data on tissue water changes and associated morphometric changes involved in the osmo-adaptation of normal brains. Our aim was to evaluate osmoadaptive responses of the healthy human brain to osmotic challenges of de- and rehydration by serial measurements of brain volume, tissue fluid, and metabolites.
\end{abstract}

MATERIALS AND METHODS: Serial TI-weighted and ${ }^{1} \mathrm{H}-\mathrm{MR}$ spectroscopy data were acquired in 15 healthy individuals at normohydration, on 12 hours of dehydration, and during 1 hour of oral rehydration. Osmotic challenges were monitored by serum measures, including osmolality and hematocrit. MR imaging data were analyzed by using FreeSurfer and LCModel.

RESULTS: On dehydration, serum osmolality increased by $0.67 \%$ and brain tissue fluid decreased by $1.63 \%$, on average. MR imaging morphometry demonstrated corresponding decreases of cortical thickness and volumes of the whole brain, cortex, white matter, and hypothalamus/thalamus. These changes reversed during rehydration. Continuous fluid ingestion of $1 \mathrm{~L}$ of water for 1 hour within the scanner lowered serum osmolality by $0.96 \%$ and increased brain tissue fluid by $0.43 \%$, on average. Concomitantly, cortical thickness and volumes of the whole brain, cortex, white matter, and hypothalamus/thalamus increased. Changes in brain tissue fluid were related to volume changes of the whole brain, the white matter, and hypothalamus/thalamus. Only volume changes of the hypothalamus/thalamus significantly correlated with serum osmolality.

CONCLUSIONS: This is the first study simultaneously evaluating changes in brain tissue fluid, metabolites, volume, and cortical thickness. Our results reflect cellular volume regulatory mechanisms at a macroscopic level and emphasize that it is essential to control for hydration levels in studies on brain morphometry and metabolism in order to avoid confounding the findings.

ABBREVIATIONS: $\mathrm{HCT}=$ hematocrit; $\mathrm{OSM}_{\text {serum }}=$ serum osmolality

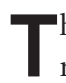
he regulation of body fluid balance inherently determines serum osmolality. Due to the high permeability of the cell membranes for water, the direction of water movement is determined

Received December 18, 2014; accepted after revision May 6, 2015

From the Department of Neuroradiology (A.B., M.B., A.J.B.), University of Heidelberg, Heidelberg, Germany; Department of Radiology (M.R.), Massachusetts General Hospital/Harvard Medical School, Boston, Massachusetts; Martinos Center for Biomedical Imaging (M.R.), Charlestown, Massachusetts; Massachusetts Institute of Technology Computer Science and AI Lab (M.R.), Cambridge, Massachusetts; Department of Psychiatry and Behavioral Sciences (B.P.), Stanford University, Stanford, California; Department of Clinical Neurology (B.P., A.J.B.), FMRIB Centre, University of Oxford, Oxford, UK; Department of Neuroradiology (G.A.H., A.J.B.), University of Würzburg, Würzburg, Germany; and Research Center for MagneticResonance-Bavaria (F.B.), Würzburg, Germany.

Please address correspondence to Armin Biller, MD, Department of Neuroradiology, University of Heidelberg, Im Neuenheimer Feld 400, 69120 Heidelberg, Germany; e-mail: armin.biller@med.uni-heidelberg.de

- Indicates open access to non-subscribers at www.ajnr.org

EIndicates article with supplemental on-line appendix and tables.

Indicates article with supplemental on-line photo.

http://dx.doi.org/10.3174/ajnr.A4508 by the osmotic gradient across the cell membrane between the intra- and extracellular space. Thus, serum hyperosmolality causes cell shrinkage, whereas hypo-osmolality induces cell swelling.

In response, the cell initiates regulatory changes to the opposite direction. Initially, cells quickly re-adjust their volume by transmembranous ion movements. Volume regulation by electrolyte shifts is limited because alterations of ion gradients across the cell membrane interfere with the structure and function of intracellular macromolecules and membrane transporters. ${ }^{1-3}$ To avoid the adverse effects of changes in ion composition, the cell uses organic osmolytes, instead of ions, which allow volume adjustment without compromising cell function. ${ }^{3-6}$ Organic osmolytes encompass polyalcohols like myo-inositol; methylamines like glycerylphosphocholine; amino $\operatorname{acids}^{7}$; and derivatives like glutamine, glutamate, $\mathrm{N}$-acetylaspartate and $\mathrm{N}$ acetyl aspartylglutamate, and creatine and taurine. . $^{3,9}$

Metabolic responses to fluid imbalance have primarily been 
studied in animals and patients with pathologies affecting serum osmolality. Previous brain morphometry findings in healthy subjects undergoing de- and rehydration have remained somewhat inconclusive and inconsistent in terms of the distribution of the changes and the structures affected. Kempton et al, ${ }^{7,10}$ Dickson et al, ${ }^{11}$ and Watson et $\mathrm{al}^{12}$ induced dehydration by thermal exercises. They reported no significant effect of dehydration on brain volume. Results on ventricular volume ranged from decrease ${ }^{12}$ to increase, ${ }^{7,10}$ and Dickson et al found no changes. ${ }^{11}$ Duning et al ${ }^{13}$ showed a $0.55 \%$ brain volume reduction after 16 hours of thirsting and a $0.72 \%$ increase after subsequent rehydration. Similarly, Streitbürger et $\mathrm{al}^{14}$ demonstrated an increase in brain volume on ingestion of 3-4 L of water; however, they failed to show an effect of dehydration on brain volume by 2 days of restricted water intake. In a study on ultramarathon runners, Freund et $\mathrm{al}^{15} \mathrm{de}-$ scribed a reversible $6 \%$ cortical volume reduction with 2 months of daily running. Currently, there are no in vivo data on tissue water changes and associated morphometric changes involved in the osmoadaptation of normal brains. In this study, we examined healthy individuals during normo-, de-, and rehydration by MR spectroscopy and morphometry and analyzed the resulting changes of global brain volume, gray/white matter volume, cortical thickness, tissue fluid, organic osmolytes, and serum parameters.

\section{MATERIALS AND METHODS \\ Ethics Statement}

The study was approved by the local Medical Ethics Committee (Faculty of Clinical Medicine, University of Würzburg), and all participants gave written informed consent before enrollment. The procedures that followed were in accordance with the Declaration of Helsinki.

\section{Participants}

We studied 15 healthy volunteers (6 women, 9 men) who received an allowance for participating in the study. Female and male participants exhibited a narrow age range (mean, $27.67 \pm 2.26$ years) and body weight (mean, $74.53 \pm 12.01 \mathrm{~kg}$ ), which did not differ across sexes $(P>.05$, Wilcoxon rank sum test). All subjects were nonsmokers and free of medication. Exclusion criteria were current or past substance abuse other than nicotine and any other psychiatric, neurologic, and medical illness.

\section{MR Imaging}

All measurements were performed on a 3T Tim Trio MR imaging system (Siemens, Erlangen, Germany) by using a transmit/receive head coil.

T1-Weighted 3D Imaging and Quantitative T1-Mapping. For volumetric and surface-based morphometry, an isotropic $(1.0 \times$ $1.0 \times 1.0 \mathrm{~mm}^{3}$ ) whole-brain T1-weighted MPRAGE sequence optimized for subsequent image data analysis was acquired ( $\mathrm{TR}=$ $2300 \mathrm{~ms}$; TE $=2.98 \mathrm{~ms}$; magnetization preparation by nonselective inversion recovery TI $=900 \mathrm{~ms}$; along with fat suppression/ fast water excitation to reduce signal from fatty bone marrow, scalp, and dura; excitation flip angle $=9^{\circ} ; 160$ sagittal slices; matrix size $=256 \times 256$ ).

For quantitative T1-relaxation-time mapping, a partial-brain
FLASH (GE Healthcare, Milwaukee, Wisconsin) sequence (TR = $330 \mathrm{~ms}, \mathrm{TE}=1.8 \mathrm{~ms}, 22$ axial slices, matrix size $=384 \times 384$, $\left.0.5 \times 0.5 \times 3.0 \mathrm{~mm}^{3}\right)$ was recorded at 2 flip angles $\left(8^{\circ}\right.$ and $\left.37^{\circ}\right)$.

${ }^{1} \mathrm{H}-\mathrm{MR}$ Spectroscopy. Localized ${ }^{1} \mathrm{H}-\mathrm{MR}$ spectroscopy data were recorded by single-voxel spectroscopy measurements using a point-resolved spectroscopy sequence $(\mathrm{TE}=30 \mathrm{~ms}, \mathrm{TR}=2000$ $\mathrm{ms}$ ). Automatic dynamic frequency correction was used for MR spectroscopy with least squares optimization across the main peaks of the water-suppressed spectra. For all subjects and each of the longitudinal point-resolved spectroscopy sequence measurements (compare "Protocol of Longitudinal Measurements"), a voxel volume of $20 \times 20 \times 20 \mathrm{~mm}^{3}$ placed in the left paracentral lobule was measured. As described earlier, ${ }^{16-18}$ placing the voxel with its inferior edge at the callosomarginal sulcus and with its posterior edge at the central sulcus allowed highly reproducible positioning. Because the voxel was placed in white matter mainly (Fig 1) systematic differences between the partial volume contribution of white matter, gray matter, and CSF were excluded (ANOVA, $P>.23$ ). No partial volume correction was performed. In vivo resonance changes were quantified by ensuring fixed scanner calibration by using in vitro references and by correcting for differences in coil load. Spectra with and without chemical shift selective water suppression were obtained ( 80 versus 16 acquisitions) to allow eddy current correction and to quantify changes of brain tissue water in the point-resolved spectroscopy sequence voxel by using the spectra without water suppression. ${ }^{19,20}$

\section{Protocol of Longitudinal Measurements}

The study consisted of $2 \mathrm{MR}$ imaging examinations measuring healthy volunteers on normo-, de-, and rehydration. The first examination studied the regularly hydrated participants, yielding a baseline ${ }^{1} \mathrm{H}-\mathrm{MR}$ spectroscopy and 3D T1-weighted dataset (normohydration). Normohydration at the time of the first examination was confirmed by blood and serum parameters (Table). Then, subjects were asked not to drink, not to eat meals containing more than $0.5 \mathrm{~L}$ of fluid, and to refrain from physical activity for 12 hours (dehydration). Subsequently, MR imaging measurements of the second examination included a ${ }^{1} \mathrm{H}-\mathrm{MR}$ spectroscopy and 3D T1-weighted dataset with subclinically dehydrated subjects. Participants then remained within the MR imaging scanner without being repositioned, and water was orally ingested via a plastic tube for 60 minutes at a rate of $1 \mathrm{~L}$ per hour (by using a MRidium MR imaging Infusion System; IRadimed, Winter Park, Florida) (rehydration). Simultaneously, 19 serial ${ }^{1} \mathrm{H}-\mathrm{MR}$ spectroscopy datasets and 1 final 3D T1-weighted structural scan were recorded during 67 minutes 4 seconds \pm 6 minutes 45 seconds. To control for circadian hormone effects, we scheduled the first MR image in the evening and the second in the morning of the following day for every participant.

For measuring serum parameters, 3 blood samples were drawn consecutively at normo-, de-, and rehydration via an antecubital IV line. Mean corpuscular hemoglobin concentration and hematocrit (HCT) values were determined by an automated counter using the electrical impedance method (Counter S-Plus IV; Beckmann Coulter, Fullerton, California).

Serum electrolytes were measured by a potentiometric autoanalyzer (Ektachem 700XRC; Eastman Kodak, Rochester, New 


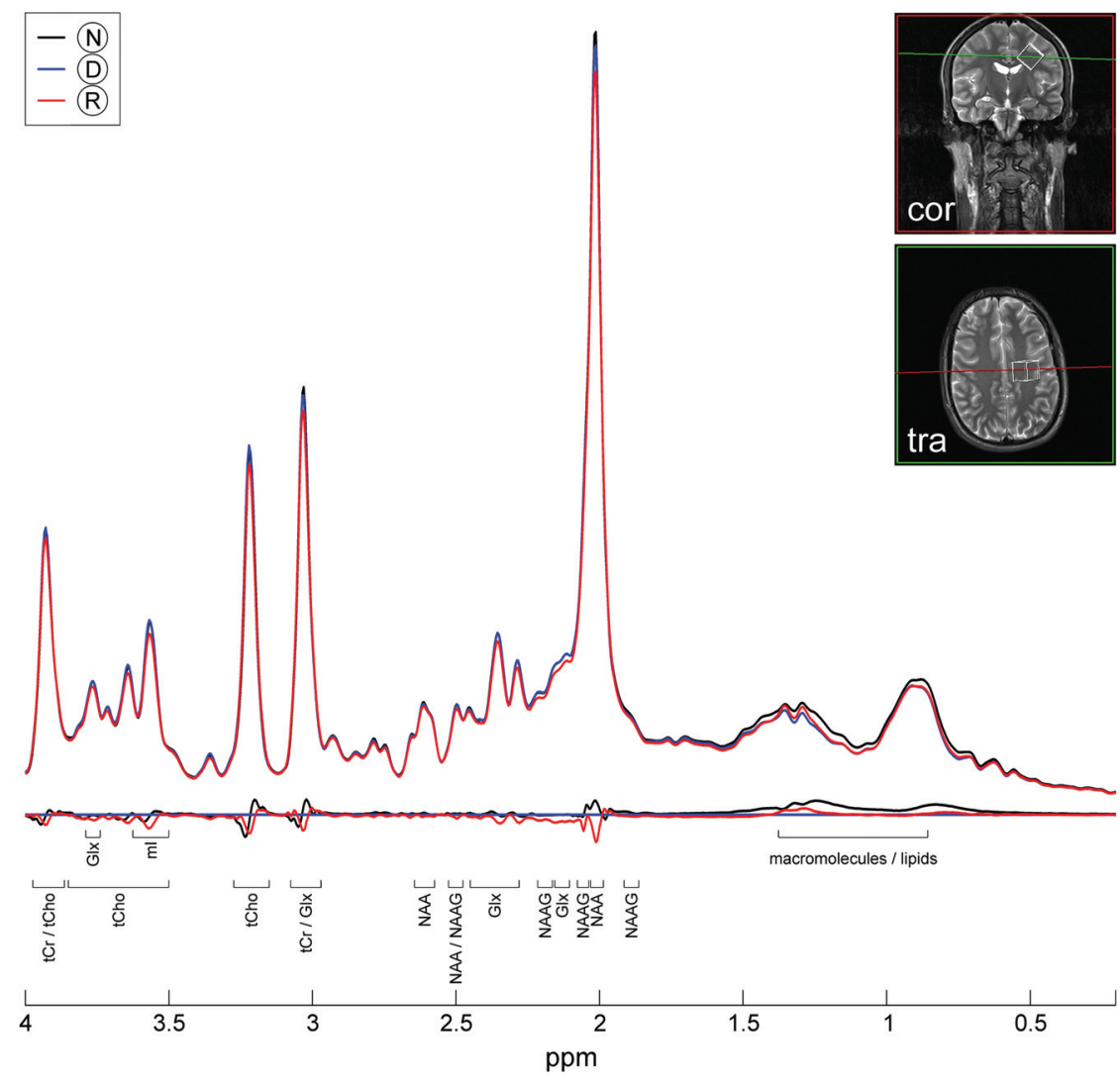

FIG 1. Representative ${ }^{1} \mathrm{H}-\mathrm{MR}$ spectroscopy spectral data fits. The voxel was placed in the left paracentral lobule. Spectral data fits (upper row) and subtracted spectra (lower row) for visualization of metabolite resonances at normo- (black line, N), de- (blue line, D), and rehydration (red line, R). $\mathrm{tCr}$ indicates total creatine, $\mathrm{ml}$, myo-inositol; tCho, total choline; NAA+NAAG, $\mathrm{N}$-acetylaspartate and $\mathrm{N}$-acetyl aspartylglutamate; Glx, glutamine + glutamate.

Blood/serum parameters during normo-, de-, and rehydration

\begin{tabular}{lccc}
\hline \multicolumn{1}{c}{ Parameter } & Normohyd & Dehyd & Rehyd \\
\hline $\mathrm{Na}^{+}(\mathrm{mmol} / \mathrm{L})$ & $137.1 \pm 2.7$ & $138.5 \pm 2.2$ & $136.9 \pm 2.3$ \\
$\mathrm{~K}^{+}(\mathrm{mmol} / \mathrm{L})$ & $4.6 \pm 0.4^{\mathrm{a}}$ & $5.2 \pm 0.6^{\mathrm{a}}$ & $4.9 \pm 0.4^{\mathrm{a}}$ \\
$\mathrm{HCT}(\%)$ & $41.9 \pm 2.9$ & $43.8 \pm 2.9$ & $42.5 \pm 2.9$ \\
$\mathrm{MCHC}(\mathrm{g} / \mathrm{dL})$ & $34.3 \pm 0.9$ & $34.3 \pm 0.8$ & $34.3 \pm 0.8$ \\
Urea $(\mathrm{mg} / \mathrm{dL})$ & $27.4 \pm 6.2$ & $26.8 \pm 5.9$ & $25.5 \pm 5.6$ \\
OSM $_{\text {serum }}(\mathrm{mOsm} / \mathrm{kg})$ & $312.7 \pm 4.8^{\mathrm{a}}$ & $314.8 \pm 4.1^{\mathrm{a}}$ & $311.8 \pm 4.7^{\mathrm{a}}$ \\
Glucose $(\mathrm{mg} / \mathrm{dL})$ & $92.1 \pm 6.8^{\mathrm{a}}$ & $84.4 \pm 6.9^{\mathrm{a}}$ & $85.5 \pm 5.9^{\mathrm{a}}$ \\
\hline
\end{tabular}

Note:- Normohyd indicates normohydration; Dehyd, dehydration; Rehyd, rehydration; MCHC, mean corpuscular hemoglobin concentration.

${ }^{\text {a }}$ Significant changes among different levels of hydration (normo-, de-, and rehydration) at type I error probabilities of $P<.05$ (1-sided $t$ tests; $d f=14$ ).

York). Serum osmolality was assessed by a cryoscopic osmometer (Osmomat 030; Gonotec, Berlin, Germany), and dehydration was confirmed by an increase and rehydration by a decrease in osmolality. Blood glucose levels were determined by photometry (Helios Alpha; Spectronic Unicam, Cambridge, UK).

\section{Data Postprocessing}

MR Morphometry. Morphometric analyses were performed to detect changes of whole brain, white matter, subcortical and cortical gray matter volume, and cortical thickness. To extract reliable cortical volume and thickness estimates, we automatically processed images by using the longitudinal stream within FreeSurfer (Version 5.3.0; http://surfer.nmr.mgh.harvard.edu/). ${ }^{21}$ For details, please see the On-line Appendix.
${ }^{1} \mathrm{H}-\mathrm{MR}$ Spectroscopy. ${ }^{1} \mathrm{H}-\mathrm{MR}$ spectroscopy data were analyzed by using the frequency-domain-fitting routine of LCModel (http://www.lcmodel.com/), ${ }^{22}$ which computes in vivo spectra as a linear combination of complete model spectra of specific in vitro metabolites predefined in basis sets. These basis sets included spectral data of alanine, aspartate, creatine, glucose, $\gamma$-aminobutyric acid, glutamine, glutamate, scyllo-inositol, myo-inositol, $\mathrm{N}$-acetylaspartate, $\mathrm{N}$-acetyl aspartylglutamate, glycerylphosphocholine, phosphocholine, guanidinoacetate, lipids, and macromolecules. Representative spectral data fits for normo-, de-, and rehydration are shown in Fig 1. For fitting macromolecule resonances, LCModel integrates a priori knowledge on macromolecules on the basis of metabolite-nulled spectra at $3 \mathrm{~T}$ (ie, macromolecule models are simulated).

On the basis of the principle of reciprocity, ${ }^{23}$ differences in coil load were corrected for by dividing the measured metabolite resonances by the required voltage amplitude to obtain maximum signal.

The integral of unsuppressed water was used as a measure of brain tissue water $\left(\mathrm{H}_{2} \mathrm{O}_{\text {brain }}\right)$. Data of each metabolite and of brain tissue fluid were normalized (by subtraction) to the second session (dehydration) by using custom-written Matlab scripts (MathWorks, Natick, Massachusetts). Outliers were defined as values exceeding 2.5 SDs, and data were corrected for outliers. Units were expressed as normalized percentage signal change. Thus, dehydration was chosen as the reference to conveniently plot successive changes (compare "MR Morphometry" above).

Criteria for assessment of spectral quality were the following: 1) the signal-to-noise ratio (defined by the ratio of the maximum in the spectrum-minus-baseline over the analysis window to twice the root-mean-square residuals, 2) the line width (roughly estimated by using the full width at half maximum), 3) the distribution of residuals, and 4) the SD. In the LCModel, SD estimates are Cramer-Rao lower bounds. Cramer-Rao lower bounds of $>50 \%$ indicate that the metabolite concentration may range from zero to twice the estimated concentration. In this study, we selected for further analysis only spectral data meeting the following: 1) a signal-to-noise ratio of $>4$; 2) full width at half maximum of $\leq 0.07 \mathrm{ppm}$; 3 ) randomly distributed residuals of $\sim 0$; and 4 ) Cramer-Rao lower bounds of $<25 \%$. 
Quantitative T1-Mapping. Quantitative T1-relaxation time maps were estimated on a voxelwise basis according to the following formula:

$$
\begin{aligned}
T 1 \mathrm{c}_{\mathrm{j}, \mathrm{k}}=T R / \ln [ & \left(\sin \left(F A_{1}\right) \times \cos \left(F A_{2}\right)-Q_{\mathrm{j}, \mathrm{k}} \times \sin \left(F A_{2}\right)\right. \\
& \left.\left.\times \cos \left(F A_{1}\right)\right) /\left(\sin \left(F A_{1}\right)-Q_{\mathrm{j}, \mathrm{k}} \times \sin \left(F A_{2}\right)\right)\right],
\end{aligned}
$$

where $T 1 c_{j, \mathrm{k}}$ is the $\mathrm{T} 1$-value, and $Q_{\mathrm{j}, \mathrm{k}}$ represents the signal intensity ratio for the voxel $(\mathrm{j}, \mathrm{k})$. For this purpose, the 2 FLASH acquisitions of the 2 flip angles $\left(F A_{1}, F A_{2}\right)$ were coregistered by using mri_robust_template (part of FreeSurfer ${ }^{24}$ ), and the upper and lower slices were discarded. To obtain separate T1-estimates for white and cortical as well as subcortical gray matter, we rigidly coregistered the segmentations/parcellations of FreeSurfer to this individual template space (by using mri_robust_register, also part of FreeSurfer), slightly eroded and applied as masks for extracting corresponding T1-relaxation times.

\section{Statistical Analyses}

All statistical analyses were performed in SPSS Statistics (Version 22; IBM Armonk, New York). On the basis of the assumption that organic osmolytes are involved in cerebral fluid regulation, myo-inositol, creatine, glutamine, glutamine+glutamate, and $\mathrm{N}$ acetyl-aspartate and $\mathrm{N}$-acetyl-aspartyl-glutamate were analyzed for changes on de- and rehydration. A repeated measures ANOVA was applied to the spectroscopic estimates of these metabolites, brain tissue fluid, and serum parameters to test for experimental changes with time (ie, different levels of hydration) by using a significance level $P \leq .05$, which corresponds to a type I error probability of $\leq 5 \%$. Thus, in the repeated measures ANOVA, the metabolite signal was the dependent measure, and time (session/level of hydration), the explanatory factor.

Post hoc $t$ test comparisons were used to assess changes between the different pairs of longitudinal time points. On the basis of physiologically appropriate assumptions about the directionality of change (ie, that osmolality should increase while brainwater resonances and volume should decrease on dehydration and vice versa on rehydration), corresponding $P$ values were estimated 1-sided. All statistical inferences were performed as paired tests.

The Pearson linear correlation coefficient $r$ was used to assess 1-sided associations among brain tissue fluid, serum parameters, and morphometry data. $P$ values were corrected for multiple comparisons (Bonferroni). Linear regression plots were generated to visualize significant associations among parameters.

Longitudinal morphometric changes of cortical surface boundaries were analyzed by using a Linear Mixed Effects Matlab toolbox (http://www.mathworks.com/help/stats/linear-mixedeffects-models.html). ${ }^{25} \mathrm{~A}$ piece-wise linear model was fitted to the data to detect changes on de- and rehydration.

\section{RESULTS}

\section{Blood/Serum Parameters}

On dehydration, the hematocrit and osmolality $\left(\mathrm{OSM}_{\text {serum }}\right)$ measures clearly indicated loss of body fluid of all participants (Table). The concentrations of $\mathrm{K}^{+}{ }_{\text {serum }}(P=.00)$ and serum glucose $(P=$ $.01)$, HCT $(P=.00)$, and $\mathrm{OSM}_{\text {serum }}(P=.03)$ changed appropri-

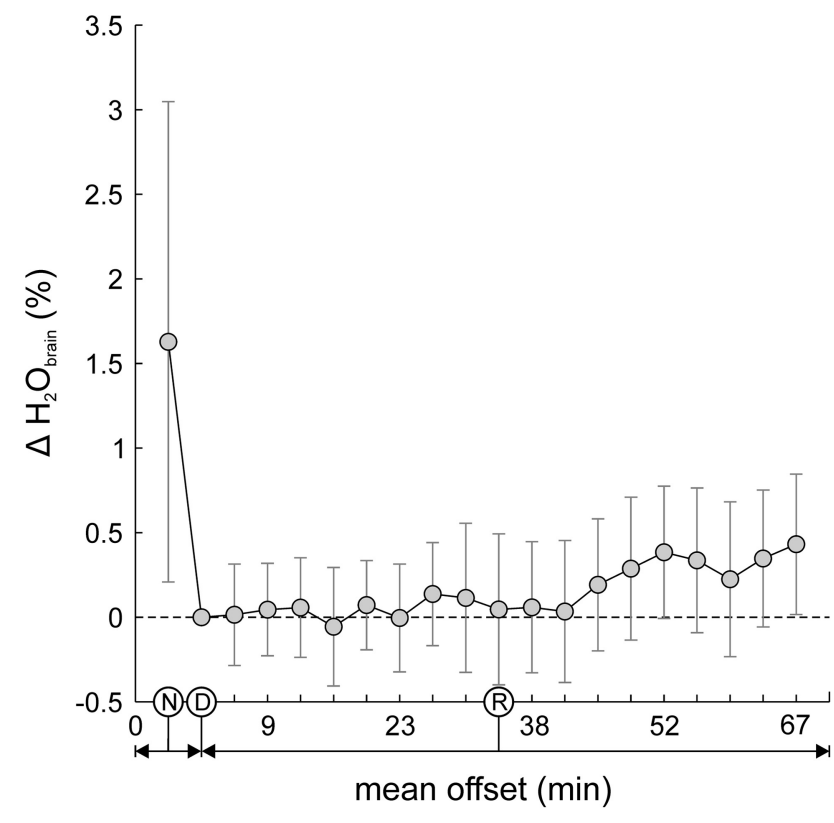

FIG 2. Serial data of brain tissue fluid $\mathrm{H}_{2} \mathrm{O}_{\text {brain. }}$ Twelve hours of thirsting (dehydration) increased serum osmolality by $0.67 \%$ and decreased $\mathrm{H}_{2} \mathrm{O}_{\text {brain }}$ by $1.63 \%$. Subsequent oral fluid intake (rehydration) during 1 hour lowered serum osmolality by $0.96 \%$ and led to an increase of $\mathrm{H}_{2} \mathrm{O}_{\text {brain }}$ by $0.43 \%$. This finding shows that even subtle changes in $\mathrm{H}_{2} \mathrm{O}_{\text {brain }}$ on minor osmotic challenges are detectable by ${ }^{1} \mathrm{H}-\mathrm{MR}$ spectroscopy.

ately on de- and rehydration, whereas changes of sodium and urea were insignificant.

None of the individuals examined met the criteria for acute hypernatremia (ie, mean sodium levels remained below 145 $\mathrm{mmol} / \mathrm{L}$ and osmolality remained below $300 \mathrm{mOsm} / \mathrm{kg}$ for all participants. Thus, blood/serum parameters indicated subclinical dehydration consistent with 12 hours without drinking overnight. No participant reported symptoms other than fatigue and thirst or exhibited clinical signs of dehydration.

\section{'H-MR Spectroscopy}

Brain Tissue Fluid. Normalized resonances of tissue fluid content of $\mathrm{H}_{2} \mathrm{O}_{\text {brain }}$ decreased on dehydration by $1.63 \pm 2.84 \%$ and steadily increased by $0.43 \pm 0.92 \%$ at the end rehydration $(F=$ $2.49, P=.00$ ) (Fig 2). Post hoc tests demonstrated a significant $\mathrm{H}_{2} \mathrm{O}_{\text {brain }}$ decrease from normo- to dehydration and significant increases during rehydration (On-line Table 1). Resonance changes of brain tissue fluid were associated with volume changes of the whole brain $(r=0.22, P=.02)$, cerebral white matter $(r=$ $0.34, P=.02)$, and the hypothalamus/thalamus $(r=0.18, P=$ .05) (On-line Table 2).

Brain Osmolytes. Representative ${ }^{1} \mathrm{H}-\mathrm{MR}$ spectroscopy spectral data fits for normo-, de-, and rehydration are shown in Fig 1 (upper row); subtracted spectral fits (lower row) represent the respective signal changes. Repeated measurements ANOVA demonstrated no significant changes in myo-inositol, creatine, glutamine+glutamate, and $\mathrm{N}$-acetylaspartate and $\mathrm{N}$-acetyl-aspartyl-glutamate in subjects on 12 hours of dehydration and during 60 minutes of rehydration. 

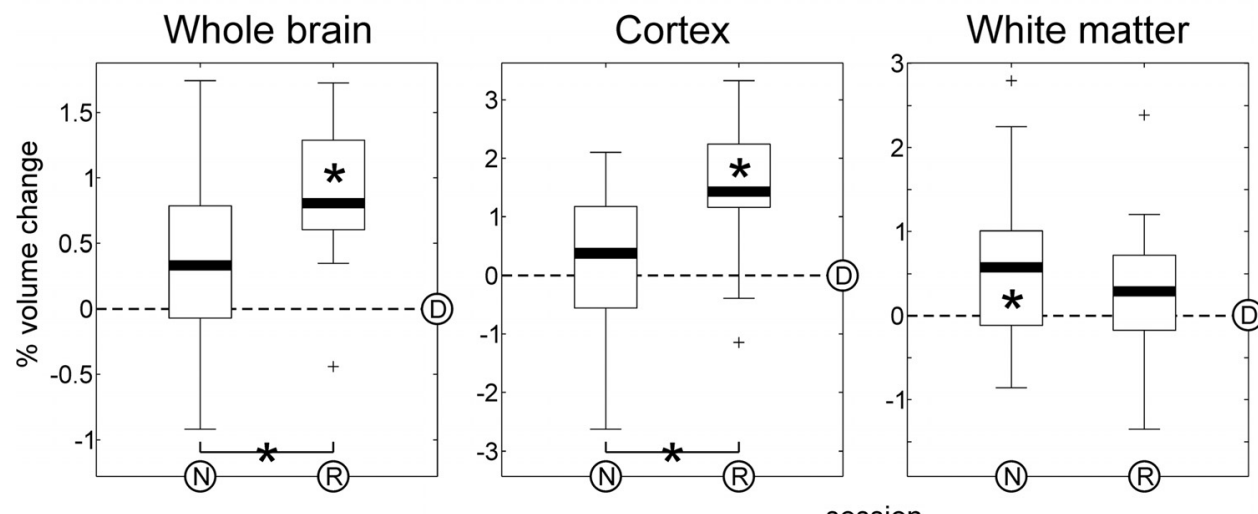

Hypothalamus /

Thalamus

session

FIG 3. Volumetric morphometry at normo-, de-, and rehydration illustrated as percentage volume change normalized to session 2 (dehydration). Volume changes of the entire brain, cerebral cortex, white matter, and hypothalamus/thalamus were significant in repeated measures ANOVA and compatible with cell shrinking during hyperosmolality and cell swelling during hypo-osmolality. Subject-specific pair-wise differences are plotted with respect to dehydration. Post hoc tests revealed hydration states with significant volume changes between each one (indicated by asterisks; for details see On-line Table 3). Box indicates upper and lower quartiles; thick black line, median; whiskers, most extreme values of the interquartile range; crosses, outliers; $\mathrm{D}$, dehydration; N, normohydration; R, rehydration; asterisk, significant difference.

\section{MR Morphometry}

Volumetry. Repeated measures statistical analyses revealed longitudinal changes of the whole brain, cortical gray and white matter volume, and the subcortical hypothalamus/thalamus volume on de- and rehydration ( $P=.00$ ) (Fig 3). Specifically, mean volumes of the whole brain, cerebral cortex, white matter, and hypothalamus/thalamus decreased on dehydration by $0.36 \pm 0.68 \%$, $0.19 \pm 1.28 \%, 0.59 \pm 0.86 \%$, and $0.30 \pm 1.80 \%$ and increased on rehydration by $0.87 \pm 0.57 \%, 1.50 \pm 1.03 \%, 0.23 \pm 0.82 \%$, and $1.11 \pm 1.28 \%$, respectively (Fig 3 ). Post hoc tests revealed significant volume changes for the whole brain, cerebral cortex, and hypothalamus/thalamus during rehydration (and between normo- and rehydration) and for white matter on dehydration (On-line Table 3). Except for white matter, the magnitude of volume changes detected from normo- to dehydration was lower than that from de- to rehydration, while the associated variance was generally higher.

Correlation analyses revealed associations between the appropriate changes of the whole-brain volume and $\mathrm{H}_{2} \mathrm{O}_{\text {brain }}(r=0.22$, $P=.02$ ) (On-line Fig $1 A$ ), of the whole-brain volume and hematocrit values $(r=-0.31, P=.00)$ (On-line Fig $1 B)$, of the cortical gray matter volume and HCT $(r=-0.22, P=.02)$ (On-line Fig $1 C)$, of the cerebral white matter volume and $\mathrm{H}_{2} \mathrm{O}_{\text {brain }}(r=$ $0.34, P=.00$ ) (On-line Fig $1 D)$, of the cerebral white matter volume and HCT $(r=-0.31, P=.00)$ (On-line Fig $1 E)$, of the hypothalamus/thalamus volume and $\mathrm{H}_{2} \mathrm{O}_{\text {brain }}(r=0.18, P=$ .05 ) (On-line Fig $1 F)$, and of the hypothalamus/thalamus volume and $\mathrm{OSM}_{\text {serum }}$ values $(r=-0.18, P=.04)$ (On-line Fig 1G) (On-line Table 2).

Cortical Thickness and Subcortical Surface Changes. Cortical thinning prevailed on dehydration, and cortical thickening, on rehydration. These changes of cortical thickness, as averaged across subjects, were not uniformly distributed over the cerebral surface (Fig 4A). Associated error probabilities (Fig 4B) revealed a similar consistent pattern and largely excluded changes to the opposite (ie, thickening on dehydration and thinning on rehydra- tion), which presumably reflect false-positive detections. Error probabilities ensure that the detected cortical thickness changes are not driven by outliers and accompanied by increased variance measures across subjects. Some areas attained high significance levels (ie, low error probabilities) (Fig 4B), despite relatively lower mean cortical thickness change (Fig $4 A$ ), due to low variability of the changes across subjects. The patterns of cortical thinning on dehydration and thickening on rehydration approximately mirrored each other and appeared quite similar (ie, symmetric, for the 2 hemispheres).

\section{Quantitative Tl-Relaxation Times}

Mean T1-relaxation times during normo-, de-, and rehydration were $1339 \pm 86.92 \mathrm{~ms}, 1314 \pm 70.26 \mathrm{~ms}$, and $1321 \pm 75.28 \mathrm{~ms}$ for the cerebral cortex; $1291 \pm 68.07 \mathrm{~ms}, 1285 \pm 66.96 \mathrm{~ms}$, and $1295 \pm 68.27 \mathrm{~ms}$ for the hypothalamus/thalamus; and $834.52 \pm$ $58.11 \mathrm{~ms}, 818.15 \pm 42.58 \mathrm{~ms}$, and $820.36 \pm 46.18 \mathrm{~ms}$ for white matter (Fig 5). Statistical analyses revealed no longitudinal differences in T1-relaxation times of the cerebral cortex $(P=.07)$, hypothalamus/thalamus $(P=.19)$, and white matter $(P=.09)$ on de- and rehydration.

\section{DISCUSSION}

In this study, for the first time, the effect of hyper- and hypoosmolality on brain tissue fluid, brain volume, and cortical thickness was monitored in vivo. These findings represent cellular changes of the volume regulatory mechanisms at a macroscopic level.

Hypernatremia is associated with brain-water loss and corresponding volume reduction, whereas hyponatremia is related to brain-water accumulation and associated volume increase. Both conditions have been extensively studied in animal experiments and reflect osmoadaptive responses of the cell to fluid imbalances. $^{26,27}$ Acute hypernatremia is defined as a plasma sodium concentration above $150 \mathrm{mmol} / \mathrm{L}$, and acute hyponatremia, as a plasma sodium concentration below $120 \mathrm{mmol} / \mathrm{L}$ developing during 24-48 hours. ${ }^{26}$ To that end, a mean plasma sodium con- 


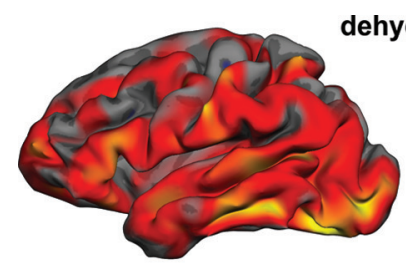

thinning

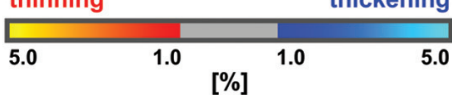

[\%]
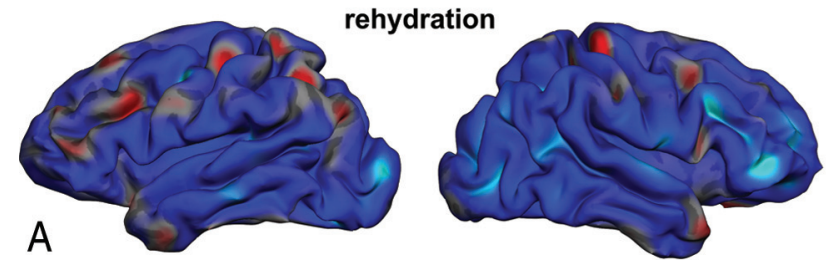

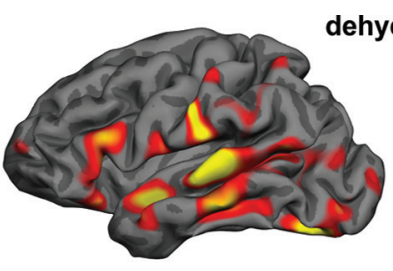

thinning
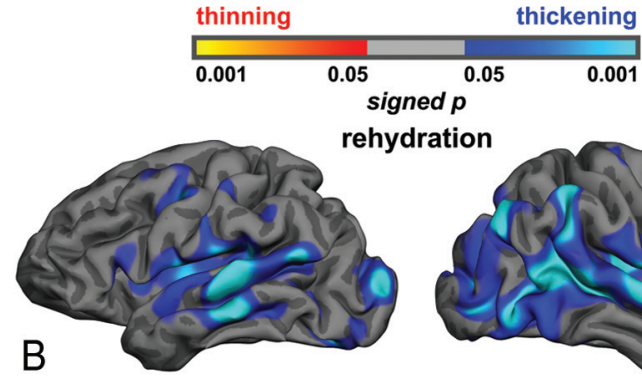

rehydration
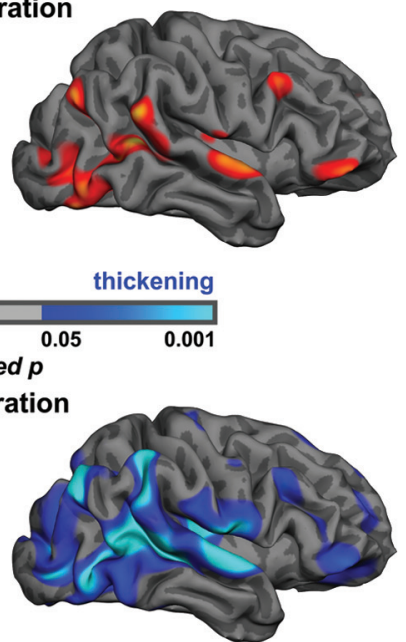

FIG 4. Cortical thickness analysis. Local changes of cortical thickness (A, red-to-yellow: for thinning on dehydration; blue-to-light blue: for thickening on rehydration). Dehydration primarily induces cortical thinning (upper row), which reverses on rehydration (bottom row). Note that these prevailing changes are not uniformly distributed over the cerebral surface. Changes on the mesial surface (not shown) were slightly less pronounced but similar. The corresponding statistical significance ( $B$, red-to-yellow: for thinning on dehydration; blue-to-light blue: for thickening upon rehydration) is expressed by increasingly lower false-positive probabilities across subjects.

Cerebral Cortex
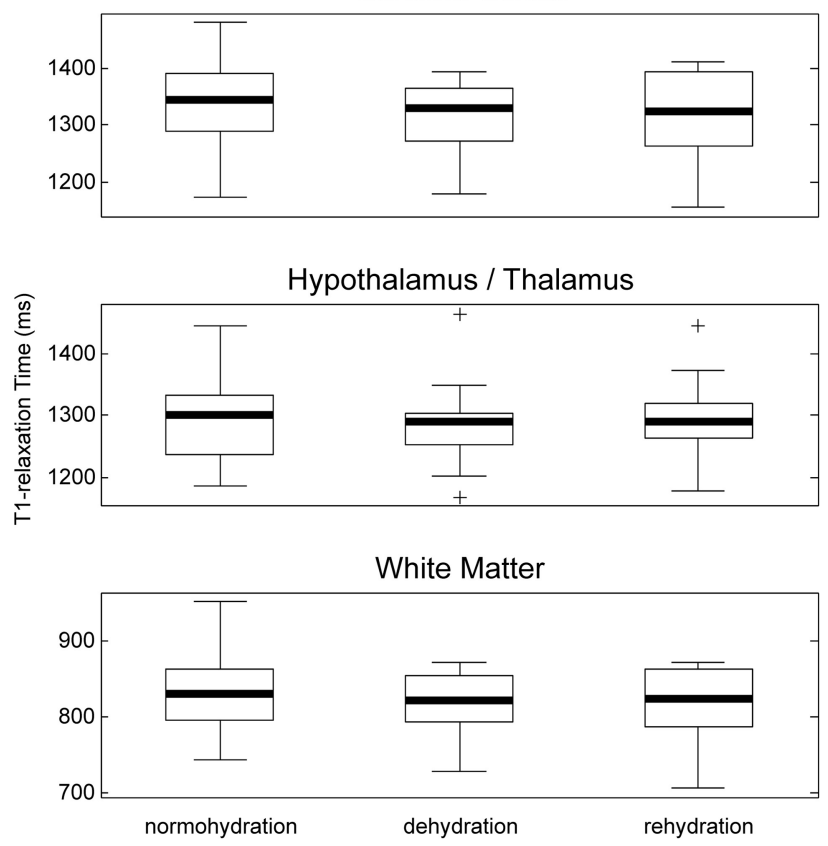

FIG 5. T1-relaxometry. Quantitative T1-relaxation times of the cerebral cortex (upper row), the subcortical gray (middle row), and white matter (bottom row) during normo-, de-, and rehydration. Statistical analyses revealed no longitudinal changes in $\mathrm{T} 1$ relaxation times. Box indicates upper and lower quartiles; thick black line, median; whiskers, most extreme values of the interquartile range; crosses, outliers.

centration of $138.5 \mathrm{mmol} / \mathrm{L}$ on dehydration and $136.9 \mathrm{mmol} / \mathrm{L}$ after rehydration as presented in our study is considered subtle. In animal models, induced hypernatremia with $200 \mathrm{mmol} / \mathrm{L}$ led to a decrease of brain-water up to $14 \%$, whereas a rapidly evoked (2 hours) hyponatremia with $119 \mathrm{mmol} / \mathrm{L}$ resulted in a $16 \%$ increase of brain-water. The rate at which osmolar stress develops defines whether the osmoadaptive capacities of the brain are exceeded. Therefore, it is plausible that a slowly induced (48 hours) hyponatremia with $107 \mathrm{mmol} / \mathrm{L}$ revealed no changes in brain-water. ${ }^{28}$
In the study here, 12 hours of thirsting elevated serum osmolality by $0.67 \%$ and resulted in $1.63 \%$ reduction of $\mathrm{H}_{2} \mathrm{O}_{\text {brain }}$. One hour of slow continuous oral fluid intake lowered serum osmolality by $0.96 \%$ and led to a $0.43 \%$ increase in $\mathrm{H}_{2} \mathrm{O}_{\text {brain }}$. This finding supports, in principle and within limits, the sensitivity and reliability of the $\mathrm{H}_{2} \mathrm{O}_{\text {brain }}$ signal, which is, especially with receive-only multichannel phased array coils, commonly used for water scaling in ${ }^{1} \mathrm{H}-\mathrm{MR}$ spectroscopy. ${ }^{19,20,29}$

On de- and rehydration, changes of the global brain volume, gray and white matter volume, hypothalamus/thalamus volume, and cortical thickness were observed, which were consistent with the processes of cell shrinkage and swelling, respectively, and are in line with findings in previous studies. ${ }^{10-13}$ Global brain volume changes on dehydration $(0.36 \%)$ and rehydration $(0.87 \%)$ are in excellent agreement with those in a previous study, ${ }^{13}$ which reported volume changes of the same magnitude after 16 hours of thirsting $(0.55 \%)$ and subsequent rehydration $(0.72 \%)$. Previous studies of Dickson et al, ${ }^{11}$ Kempton et al, ${ }^{10}$ and Watson et al, ${ }^{12}$ which induced dehydration by thermal exercises, failed to demonstrate brain volume changes.

Freund et $\mathrm{al}^{15}$ demonstrated a reversible volume reduction of cerebral gray matter (6\%) after 2 months of daily running during an ultramarathon, which is in line with the reversible cortical thinning $(0.19 \%)$ on dehydration reported in our study. On the other hand, a recent study with low sample size $e^{14}$ failed to reveal thinning of the cerebral cortex and shrinking of the hypothalamus/thalamus, which are reversed on rehydration. Reversible cortical thinning by short-term dehydration is not uniformly distributed over the cerebral surface (Fig 4) (ie, the brain does not seem to simply shrink by global scaling during dehydration). Instead, detected changes of cortical thickness reveal some but no exclusive overlap with the following: 1) known areas of pronounced cortical thickness ${ }^{30}$; and 2) atrophy patterns found in Alzheimer disease, ${ }^{31}$ cerebrovascular dementia, ${ }^{32}$ and eating disorders, ${ }^{33}$ for example. Also, more generally, brain volume changes due to osmotic stress are in/near the magnitude of 
changes attributed to annual volume decrease by aging $(0.2 \%),{ }^{34,35}$ Alzheimer disease (2\%), Lewy body dementia $(1.4 \%)$, or vascular dementia $(1.9 \%)$. $^{36}$ These results emphasize that longitudinal changes and cross-sectional differences of cortical thickness in conditions accompanied by altered fluid intake (such as dementias or eating disorders) can be confounded by deand rehydration, which may then be mistaken for brain atrophy or even regeneration.

Whole-brain, white matter, and hypothalamus/thalamus volumes demonstrated changes related to those in brain tissue fluid. This finding is further supported by the inverse correlation between HCT and volume changes of the whole brain, cerebral cortex, and cerebral white matter. The only brain structure that demonstrated an association between its volume and serum osmolality changes was the hypothalamus/thalamus. This finding is consistent with the fact that the hypothalamus includes magnocellular neurosecretory cells of the paraventricular and supraoptic nucleus, which are able to intrinsically detect and respond to changes in osmolality. ${ }^{37}$ The magnocellular neurosecretory cell volume has been shown to be inversely proportional to the osmolality of the extracellular fluid. ${ }^{38}$ Moreover, in a magnocellular neurosecretory cell subset of the paraventricular and supraoptic nucleus, vasopressin is synthesized. Axons project into the neurohypophysis, where vasopressin release occurs. Thus, the association between volume changes of the hypothalamus/thalamus as found in our study may reflect the relationship between magnocellular neurosecretory cell volume and osmolality of the extracellular fluid. However, we acknowledge that magnocellular neurosecretory cells are distributed over different subcortical gray matter nuclei and cannot be directly assessed by MR imaging at $3 \mathrm{~T}$.

No statistically significant changes of cerebral osmolytes on dehydration or after rehydration were observed. This finding may be due to these changes falling below the between- and withinsession reproducibility limits of the spectroscopy measurements. Note that the between-session variance exceeded the within-session variance across subjects for all morphometric and spectroscopic measures studied (Figs 2, 3, and 5), which presumably results from repositioning and reshimming. Alternatively, 12 hours of mild dehydration may not produce changes in organic osmolytes large enough to be detectable by MR spectroscopy-at least not in all individuals - that is, osmolytes may already act as osmotic active substrates in some individuals but not in others. Although the resulting metabolite data might demonstrate plausible kinetics of organic osmolytes in a subset of individuals, there is a high variance in the data across subjects, which emphasizes such interindividual differences. In this study, mild dehydration was associated with a $0.67 \%$ increase in serum osmolality, and rehydration resulted in a $0.29 \%$ decrease in serum osmolality. For comparison, Videen et $\mathrm{al}^{39}$ reported cerebral osmolyte changes (reduction of myo-inositol, choline, total creatine, and $N$-acetylaspartate) on hyponatremia in patients with pituitary tumors, congestive heart failure, or syndrome of inappropriate antidiuretic hormone secretion associated with an average $12.98 \%$ reduction in serum osmolality. Lien et $\mathrm{al}^{40}$ examined severe hypernatremia in rats, which led to a mean $33.55 \%$ increase in serum osmolality and also demonstrated changes in organic osmolytes (increase of myo-inositol, choline, phosphocreatine, glutamine, and glutamate) in brain tissue.

Limitations of this study are methodologically inherent because assigning resonances of ${ }^{1} \mathrm{H}-\mathrm{MR}$ spectroscopy data to metabolites, for example, is itself error-prone. Data quality and selection of an adequate fitting routine are therefore essential.

At least in theory, morphometric changes may also result from purely physical changes in tissue relaxation times and contrast induced by fluid changes influencing tissue segmentation. However, there were no changes in T1-relaxation times of the cerebral cortex and the subcortical gray and the white matter among normo-, de-, and rehydration, while the average T1-values themselves were in excellent agreement with previous data. ${ }^{41}$ Also, the correlations between morphometry measures and serum parameters support physiologic effects. Moreover, whether physiologic and/or physical, the key message is that hydration levels constitute an important confound for morphometric studies, and this is the first study demonstrating relevant changes of cortical thickness related to subclinical dehydration and rehydration. Brain tissue fluid resonances, rapidly assessed by unsuppressed ${ }^{1} \mathrm{H}$-MR spectroscopy, are suitable for water scaling and, along with serum parameters, also correlate with whole-brain, white matter, and hypothalamus/thalamus volume changes.

\section{CONCLUSIONS}

This study suggests the following: 1) Morphometric brain changes during de- and rehydration match the concept of osmotically induced cell volume changes, and 2) the cerebral cortex, white matter, and the hypothalamus/thalamus are affected by these changes. Our results emphasize that it is essential to control for hydration levels in any study on cerebral morphometry or metabolism to avoid confounding the findings. This is especially important because hydration levels can systematically differ across population samples and longitudinal follow-up, in particular for patients with dementias, eating disorders, and other conditions accompanied by even slightly altered fluid intake.

\section{ACKNOWLEDGMENTS}

We thank Professor Andreas Draguhn (Institute of Physiology and Pathophysiology, Division of Neuro- and Sensory Physiology, University of Heidelberg, Germany) for critical reading of the manuscript and very helpful comments.

Disclosures: Martin Reuter-RELATED: Grant: National Institutes of Health, Grant K25 CA181632. * Martin Bendszus_UNRELATED: Consultancy: Codman; Payment for Lectures (including service on Speakers Bureaus): Novartis, Guerbet, Codman, Roche. *Money paid to the institution.

\section{REFERENCES}

1. Buche A, Colson P, Houssier C. Effect of organic effectors on chromatin solubility, DNA-histone $\mathrm{H} 1$ interactions, DNA and histone H1 structures. J Biomol Struct Dyn 1993;11:95-119 CrossRef Medline

2. Iyer SS, Pearson DW, Nauseef WM, et al. Evidence for a readily dissociable complex of p47phox and p67phox in cytosol of unstimulated human neutrophils. J Biol Chem 1994;269:22405-11 Medline

3. Lang F, Busch GL, Ritter M, et al. Functional significance of cell volume regulatory mechanisms. Physiol Rev 1998;78:247-306 Medline

4. Burg MB. Molecular basis for osmoregulation of organic osmolytes

AJNR Am J Neuroradiol 36:2277-84 Dec 2015 www.ajnr.org

2283 
in renal medullary cells. J Exp Zool 1994;268:171-75 CrossRef Medline

5. Handler JS, Kwon HM. Regulation of renal cell organic osmolyte transport by tonicity. Am J Physiol 1993;265(6 pt 1):C1449-55 Medline

6. Kinne RK. The role of organic osmolytes in osmoregulation: from bacteria to mammals. J Exp Zool 1993;265:346-55 CrossRef Medline

7. Kempton MJ, Ettinger U, Foster R, et al. Dehydration affects brain structure and function in healthy adolescents. Hum Brain Mapp 2011;32:71-79 CrossRef Medline

8. Law RO. Amino acids as volume-regulatory osmolytes in mammalian cells. Comp Biochem Physiol A Comp Physiol 1991;99:263-77 CrossRef Medline

9. Garcia-Perez A, Burg MB. Role of organic osmolytes in adaptation of renal cells to high osmolality. J Membr Biol 1991;119:1-13 CrossRef Medline

10. Kempton MJ, Ettinger U, Schmechtig A, et al. Effects of acute dehydration on brain morphology in healthy humans. Hum Brain Mapp 2009;30:291-98 CrossRef Medline

11. Dickson JM, Weavers HM, Mitchell N, et al. The effects of dehydration on brain volume - preliminary results. Int J Sports Med 2005; 26:481-85 CrossRef Medline

12. Watson $P$, Head K, Pitiot A, et al. Effect of exercise and heat-induced hypohydration on brain volume. Med Sci Sports Exerc 2010;42:2197204 CrossRef Medline

13. Duning T, Kloska S, Steinsträter O, et al. Dehydration confounds the assessment of brain atrophy. Neurology 2005;64:548-50 CrossRef Medline

14. Streitbürger DP, Möller HE, Tittgemeyer M, et al. Investigating structural brain changes of dehydration using voxel-based morphometry. PLoS One 2012;7:e44195 CrossRef Medline

15. Freund W, Faust S, Birklein F, et al. Substantial and reversible brain gray matter reduction but no acute brain lesions in ultramarathon runners: experience from the TransEurope-FootRace Project. $B M C$ Med 2012;10:170 CrossRef Medline

16. Biller A, Bartsch AJ, Homola G, et al. The effect of ethanol on human brain metabolites longitudinally characterized by proton MR spectroscopy. J Cereb Blood Flow Metab 2009;29:891-902 CrossRef Medline

17. Bartsch AJ, Homola G, Biller A, et al. Manifestations of early brain recovery associated with abstinence from alcoholism. Brain 2007; 130(pt 1):36-47 CrossRef Medline

18. Bendszus M, Weijers HG, Wiesbeck G, et al. Sequential MR imaging and proton MR spectroscopy in patients who underwent recent detoxification for chronic alcoholism: correlation with clinical and neuropsychological data. AJNR Am J Neuroradiol 2001;22:1926-32 Medline

19. Gasparovic C, Neeb H, Feis DL, et al. Quantitative spectroscopic imaging with in situ measurements of tissue water T1, T2, and density. Magn Reson Med 2009;62:583-90 CrossRef Medline

20. Soher BJ, Hurd RE, Sailasuta N, et al. Quantitation of automated single-voxel proton MRS using cerebral water as an internal reference. Magn Reson Med 1996;36:335-39 CrossRef Medline

21. Reuter M, Schmansky NJ, Rosas HD, et al. Within-subject template estimation for unbiased longitudinal image analysis. Neuroimage 2012;61:1402-18 CrossRef Medline

22. Provencher SW. Automatic quantitation of localized in vivo $\mathbf{1 H}$ spectra with LCModel. NMR Biomed 2001;14:260-64 CrossRef Medline

23. Brooks JC, Roberts N, Kemp GJ, et al. Magnetic resonance imagingbased compartmentation and its application to measuring metabolite concentrations in the frontal lobe. Magn Reson Med 1999;41: 883-88 CrossRef Medline

24. Reuter M, Rosas HD, Fischl B. Highly accurate inverse consistent registration: a robust approach. Neuroimage 2010;53:1181-96 CrossRef Medline

25. Bernal-Rusiel JL, Greve DN, Reuter M, et al. Statistical analysis of longitudinal neuroimage data with linear mixed effects models. Neuroimage 2013;66:249-60 CrossRef Medline

26. Gullans SR, Verbalis JG. Control of brain volume during hyperosmolar and hypoosmolar conditions. Ann Rev Med 1993;44:289-301 CrossRef Medline

27. Verbalis JG. Brain volume regulation in response to changes in osmolality. Neuroscience 2010;168:862-70 CrossRef Medline

28. Vajda Z, Berényi E, Bogner $\mathrm{P}$, et al. Brain adaptation to water loading in rabbits as assessed by NMR relaxometry. Pediatr Res 1999;46: 450-54 CrossRef Medline

29. Gasparovic C, Song T, Devier D, et al. Use of tissue water as a concentration reference for proton spectroscopic imaging. Magn Reson Med 2006;55:1219-26 CrossRef Medline

30. Fischl B, Dale AM. Measuring the thickness of the human cerebral cortex from magnetic resonance images. Proc Natl Acad Sci U S A 2000;97:11050-55 CrossRef Medline

31. Becker JA, Hedden T, Carmasin J, et al. Amyloid- $\boldsymbol{\beta}$ associated cortical thinning in clinically normal elderly. Ann Neurol 2011;69: 1032-42 CrossRef Medline

32. Kim HJ, Ye BS, Yoon CW, et al. Cortical thickness and hippocampal shape in pure vascular mild cognitive impairment and dementia of subcortical type. Eur J Neurol 2014;21:744-51 CrossRef Medline

33. Joos A, Klöppel S, Hartmann A, et al. Voxel-based morphometry in eating disorders: correlation of psychopathology with grey matter volume. Psychiatry Res 2010;182:146-51 CrossRef Medline

34. Good CD, Johnsrude IS, Ashburner J, et al. A voxel-based morphometric study of ageing in 465 normal adult human brains. Neuroimage 2001;14(1 pt 1):21-36 CrossRef Medline

35. Smith CD, Chebrolu H, Wekstein DR, et al. Age and gender effects on human brain anatomy: a voxel-based morphometric study in healthy elderly. Neurobiol Aging 2007;28:1075-87 CrossRef Medline

36. O'Brien JT, Paling S, Barber R, et al. Progressive brain atrophy on serial MRI in dementia with Lewy bodies, $\mathrm{AD}$, and vascular dementia. Neurology 2001;56:1386-88 CrossRef Medline

37. Bourque CW. Central mechanisms of osmosensation and systemic osmoregulation. Nat Rev Neurosci 2008;9:519-31 CrossRef Medline

38. Zhang Z, Bourque CW. Osmometry in osmosensory neurons. Nat Neurosci 2003;6:1021-22 CrossRef Medline

39. Videen JS, Michaelis T, Pinto P, et al. Human cerebral osmolytes during chronic hyponatremia: a proton magnetic resonance spectroscopy study. J Clin Invest 1995;95:788-93 CrossRef Medline

40. Lien YH, Shapiro JI, Chan L. Effects of hypernatremia on organic brain osmoles. J Clin Invest 1990;85:1427-35 CrossRef Medline

41. Wansapura JP, Holland SK, Dunn RS, et al. NMR relaxation times in the human brain at 3.0 Tesla. J Magn Reson Imaging 1999;9:531-38 CrossRef Medline 